\title{
Contributing countries
}

(C) European Association for Predictive, Preventive and Personalised Medicine 2011

$>$ Austria
$>$ Australia
$>$ Belgium
$>$ Bulgaria
$>$ Canada
$>$ Chile
$>$ China
$>$ Croatia
$>$ Czech Republic
$>$ Denmark
$>$ Estonia
$>$ Finland
$>$ France
$>$ Georgia
$>$ Greece
$>$ Germany
$>$ Hungary
$>$ India
$>$ Ireland
$>$ Israel
$>$ Italy
$>$ Japan

$$
\begin{aligned}
& >\text { Lithuania } \\
& >\text { Macedonia, FYROM } \\
& >\text { Malta } \\
& >\text { Mexico } \\
& >\text { Poland } \\
& >\text { Portugal } \\
& >\text { Romania } \\
& >\text { Russia } \\
& >\text { Serbia } \\
& >\text { Slovak Republic } \\
& >\text { Slovenia } \\
& >\text { South Africa } \\
& >\text { Spain } \\
& >\text { Sweden } \\
& >\text { Switzerland } \\
& >\text { Taiwan, ROC } \\
& >\text { The Netherlands } \\
& >\text { Turkey } \\
& >\text { UK } \\
& >\text { Ukraine } \\
& >\text { USA }
\end{aligned}
$$

